\title{
Small Modular PWR Design for TRU Recycling with McCARD-MASTER Two-Step Procedure
}

\author{
Dae Hee Hwang, Ser Gi Hong* \\ Department of Nuclear Engineering, Kyung Hee University \\ 1732, Deogyeong-daero, Giheung-gu, Yongin-si, Gyeonggi-do, 17104, Republic of Korea \\ imvenatir@,hanmail.net, sergihong@khu.ac.kr*
}

\begin{abstract}
In our previous study, a small modular PWR core was designed for TRU (Transuranics) recycling with multi-recycling scheme with a typical two-step procedure using DeCART2D/MASTER code system in which the lattice analysis for producing homogenized group constant was performed by DeCART2D while whole core analysis was conducted by MASTER code. However, the neutron spectrum hardening of the LWR core loaded with TRU requires validating the multi-group cross section library and resonance self-shielding treatment method in lattice calculation. In this study, a new procedure using McCARD/MASTER was used to analyze the SMR core, in which the lattice calculation was performed by a Monte Carlo code called McCARD with a continuous energy library to generate homogenized two-group assembly cross sections. The SMR core analysis was performed to show neutronic characteristics and TRU mass flow in the SMR core with TRU multi-recycling. The result shows that the analyses on the neutronic characteristics and TRU mass flow using the McCARD/MASTER code system showed good agreement with the previous ones using the DeCART2D/MASTER code system. The neutronic characteristics of each cycle of the core satisfied the typical limit of a commercial PWR core and the SMR core consumes effectively TRU with net TRU consumption rates of $8.46 \sim 14.33 \%$.
\end{abstract}

KEYWORDS: McCARD/MASTER, small modular PWR, TRU multi-recycling

\section{INTRODUCTION}

Nowadays, one of the most important issues in nuclear industry is safe management and disposal of spent nuclear fuel which contains high level radioactive materials. Several concepts such as CORAIL (COmbustible Recyclage AILot), and CONFU (COmbined NonFertile and Uranium) have been suggested to reduce the inventory and radiotoxicity of spent nuclear fuel by recycling TRUs in PWRs [1-4]. Recently, we have studied the TRU transmutation with a multi-recycling scheme in small modular LWR core [5-7]. Especially, a specialized fuel assembly composed of MOX (Mixed OXide) and FCM (Fully Ceramic Micro-encapsulated) fuel rods was suggested to effectively consume TRUs. With this fuel assembly, the amount of consumed TRU was considerably larger than the amount of produced TRU during depletion. In this concept, only TRU in MOX rod was recycled while the TRU in FCM rod was not recycled due to its high burnup (i.e., high TRU consumption) [5-7]. In the previous study, a deterministic two-step procedure with DeCART2D/MASTER codes was used for the small modular LWR core analysis with multi-recycling of TRU. DeCARD2D [8] has been developed at Korea Atomic Energy 
Research Institute (KAERI) for generating few group homogenized neutron cross section data, which solves transport equation by using MOC with the 47 group flux-weighted neutron cross section library based on ENDF.B-VII.r1. The whole core analysis was performed by MASTER [9] which is the nodal diffusion core analysis code developed at KAERI. When TRU nuclides are loaded in LWR core, which makes the neutron spectrum hardened due to high thermal absorption of TRU, it is needed to validate and verify the multi-group cross section library and resonance self-shielding treatment method in the lattice calculations. In this study, the small modular LWR core analysis was performed by a new two-step procedure with McCARD/MASTER codes in which the few group homogenized fuel assembly cross sections are produced with Monte Carlo depletion calculations and continuous energy cross sections. In this work, we performed the detailed neutronic analysis on the PWR-based SMR core.

\section{COMPUTATIONAL METHODS}

In this study, two-step procedure was used for analyzing neutronic characteristics of the small modular LWR core with TRU multi-recycling scheme. The lattice calculation for producing few group homogenized neutron cross section data was performed by a Monte Calro code called McCARD [10] in which the few group homogenized fuel assembly cross sections are produced with the continuous energy library. In the calculation using McCARD, the number of particles per cycle and cycles were set to 10,000 and 120 (20 inactive cycle, and 100 active cycle) such that the standard deviation of infinite multiplication factor was within $80 \mathrm{pcm}$. The whole core analysis was performed by MASTER [9] which has been developed for nuclear analysis and core design using multi-group nodal diffusion methods. The initial TRU feed composition for FCM and MOX fuels corresponds to the PWR spent fuel having 50 MWD/kg burnup and 10 years cooling. Table I shows the initial composition of each TRU nuclides. In this study, the TRU recycling in the SMR core was modeled using a coupling of McCARD, MASTER, and ORIGEN2 [11]. After the depletion calculation of the core using MASTER for each cycle, the average discharge burnups for the discharged fuel assemblies were used in McCARD fuel assembly calculations to estimate the composition of the fuel assemblies and then ORGEN2 were used to determine the TRU composition after cooling time. We assumed a 7 years cooling before loading into the core after discharge and reprocessing including fuel fabrication. Then, new TRU compositions are used in McCARD calculations for the homogenized cross section of the new fuel assemblies which are to be loaded in the core for the next cycle.

Table I. Initial TRU composition corresponding to burnup of $50 \mathrm{MWD} / \mathrm{kg}$ and cooling time of 10 years

\begin{tabular}{|c|c|}
\hline TRU nuclides & Composition (wt\%) \\
\hline NP237 & 6.92976 \\
\hline PU238 & 2.52569 \\
\hline PU239 & 46.24361 \\
\hline PU240 & 18.16532 \\
\hline PU241 & 9.99770 \\
\hline PU242 & 7.22376 \\
\hline AM241 & 6.60611 \\
\hline AM242M & 0.01900 \\
\hline AM243 & 1.79111 \\
\hline CM242 & 0.00005 \\
\hline CM243 & 0.00535 \\
\hline CM244 & 0.45795 \\
\hline CM245 & 0.03028 \\
\hline CM246 & 0.00431 \\
\hline Total & 100.00 \\
\hline
\end{tabular}




\section{DESIGN AND ANALYSIS OF FUEL ASSEMBLY}

Table II shows the design features of the fuel assemblies composed of MOX rods and FCM. The fuel assemblies were designed based on WH $17 \times 17$ fuel assembly. There are four types of fuel assemblies having different amount of burnable absorbers. The B0 fuel assembly having no burnable absorber consists of $212 \mathrm{MOX}$ rods and $52 \mathrm{FCM}$ TRISO rods. The $\mathrm{B} 1^{\wedge} \mathrm{B} 3$ fuel assemblies are loaded with the burnable absorber of FCM BISO particle having $\mathrm{Gd}_{2} \mathrm{O}_{3}$ kernel. In these fuel assemblies, $32 \mathrm{MOX}$ rods are replaced with FCM BISO rods in order to reduce the amount of initial HM (Heavy Metal) loading, which results in neutron spectrum softening and improving the effectiveness of burnable absorber. The packing fractions of BISO particles vary from 2 to $18 \%$. In MOX rods, the fuel pellets are composed of $\mathrm{UO}_{2}-7.31$

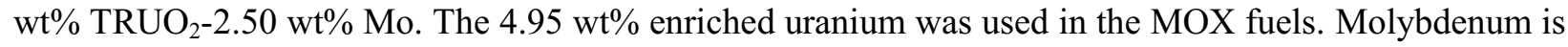
admixed in pellets in order to have the accident tolerance by improving the thermal conductivity and fission product retention capability of the pellets [12]. In FCM TRISO rods, the kernel consists of only $\mathrm{TRUO}_{2}$ for deep burning of TRU nuclides. The pellet densities for MOX and FCM TRISO rod fuels were determined based on the $96 \% \mathrm{TD}$ of $\mathrm{UO}_{2}$ fuel. The configuration of the fuel assemblies are depicted in Fig. 1.

Table II. Design specifications of the fuel assemblies composed of MOX rods and FCM rods

\begin{tabular}{|c|c|c|c|c|}
\hline Parameter & B0 & B1 & B2 & B3 \\
\hline Rod array & \multicolumn{4}{|c|}{$17 \times 17$} \\
\hline Pellet radius $(\mathrm{cm})$ & \multicolumn{4}{|c|}{0.4095} \\
\hline Clad. thickness $(\mathrm{cm})$ & \multicolumn{4}{|c|}{0.0655} \\
\hline Rod diameter $(\mathrm{cm})$ & \multicolumn{4}{|c|}{0.95} \\
\hline Clad. material & \multicolumn{4}{|c|}{ Zircaloy-4 } \\
\hline Pin pitch $(\mathrm{cm})$ & \multicolumn{4}{|c|}{1.2234} \\
\hline Assembly pitch $(\mathrm{cm})$ & \multicolumn{4}{|c|}{20.879} \\
\hline Pitch to diameter ratio & \multicolumn{4}{|c|}{1.288} \\
\hline \multicolumn{5}{|l|}{ MOX rod } \\
\hline The number of rods & 212 & & 180 & \\
\hline Pellet material & \multicolumn{4}{|c|}{$\mathrm{UO}_{2}-\mathrm{TRUO}_{2}(7.31 \mathrm{wt} \%)-\mathrm{Mo}(2.5 \mathrm{wt} \%)$} \\
\hline U enrichment (wt\%) & \multicolumn{4}{|c|}{4.95} \\
\hline Density $\left(\mathrm{g} / \mathrm{cm}^{3}\right)$ & \multicolumn{4}{|c|}{10.392} \\
\hline FCM TRISO rod & \multicolumn{4}{|c|}{-} \\
\hline The number of rods & 52 & & 52 & \\
\hline Kernel material & \multicolumn{4}{|c|}{$\mathrm{TRUO}_{2}$} \\
\hline Density $\left(\mathrm{g} / \mathrm{cm}^{3}\right)$ & \multicolumn{4}{|c|}{10.430} \\
\hline Kernel diameter $(\mu \mathrm{m})$ & \multicolumn{4}{|c|}{800} \\
\hline Buffer thickness $(\mu \mathrm{m})$ & \multicolumn{4}{|c|}{80} \\
\hline IPyC thickness $(\mu \mathrm{m})$ & \multicolumn{4}{|c|}{20} \\
\hline SiC thickness $(\mu \mathrm{m})$ & \multicolumn{4}{|c|}{35} \\
\hline OPyC thickness $(\mu \mathrm{m})$ & \multicolumn{4}{|c|}{20} \\
\hline Packing fraction $(\%)$ & \multicolumn{4}{|c|}{40} \\
\hline FCM BISO rod & \multicolumn{4}{|c|}{-} \\
\hline The number of rods & 0 & \multicolumn{3}{|c|}{32} \\
\hline Kernel material & - & \multicolumn{3}{|c|}{$\mathrm{Gd}_{2} \mathrm{O}_{3}$} \\
\hline Kernel diameter $(\mu \mathrm{m})$ & - & \multicolumn{3}{|c|}{500} \\
\hline Buffer thickness $(\mu \mathrm{m})$ & - & \multicolumn{3}{|c|}{18} \\
\hline OPyC thickness $(\mu \mathrm{m})$ & - & \multicolumn{3}{|c|}{23} \\
\hline Packing fraction $(\%)$ & - & 2 & 18 & 20 \\
\hline
\end{tabular}




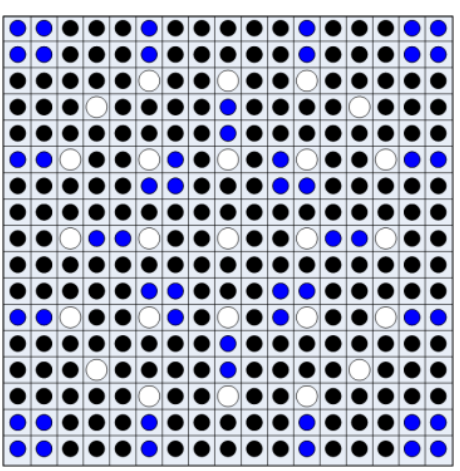

(a) B0

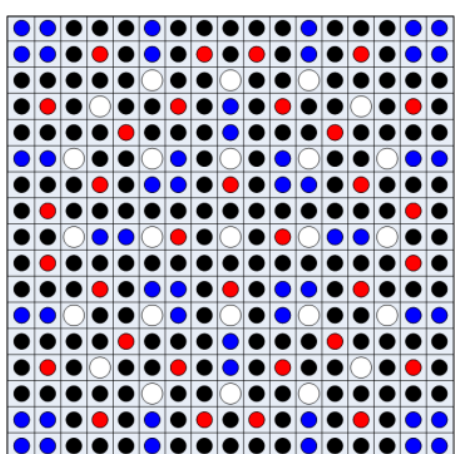

(b) B1-B3
$\operatorname{MOX} \operatorname{rod}\left(\mathrm{UO}_{2}+\mathrm{TRUO}_{2}\right)$

FCM BISO $\operatorname{rod}\left(\mathrm{Gd}_{2} \mathrm{O}_{3}\right)$

FCM TRISO rod $\left(\mathrm{TRUO}_{2}\right)$

Water hole

Figure 1. Configuration of the $17 \times 17$ fuel assemblies composed of MOX rods and FCM rods

Figure 2 compares the evolutions of the infinite multiplication factors $\left(\mathrm{k}_{\text {inf }}\right)$ calculated by DeCART2D and McCARD for each fuel assembly. As shown in the figure, all the $\mathrm{k}_{\text {inf }}$ values calculated by McCARD are estimated to be large than those of DeCART2D at BOC. The differences of the reactivity at BOC between DeCART2D and McCARD were $338 \mathrm{pcm}, 366 \mathrm{pcm}, 378 \mathrm{pcm}$ and $610 \mathrm{pcm}$ for B0, B1, B2 and B3 fuel assemblies, respectively. That is, the reactivity difference at BOC increases as the amount of burnable absorber increases. The comparison of the $\mathrm{k}_{\text {inf }}$ values calculated by DeCART2D and McCARD shows a good agreement each other throughout all the burnup steps.

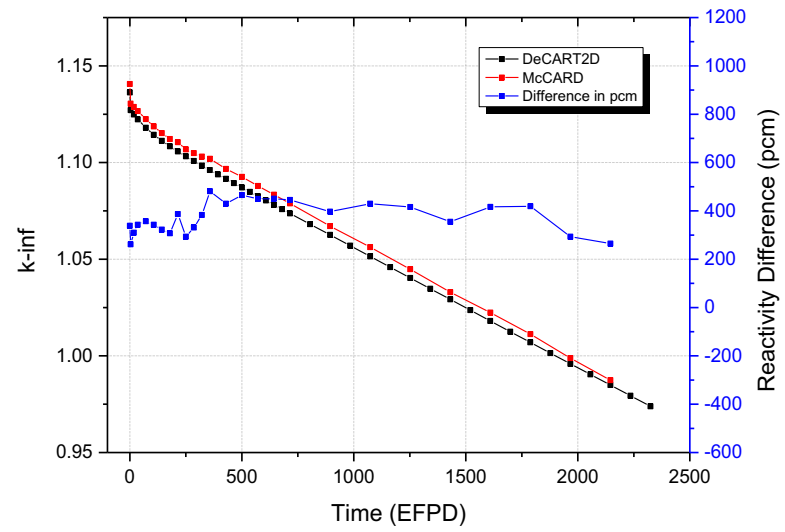

(a) B0 fuel assembly

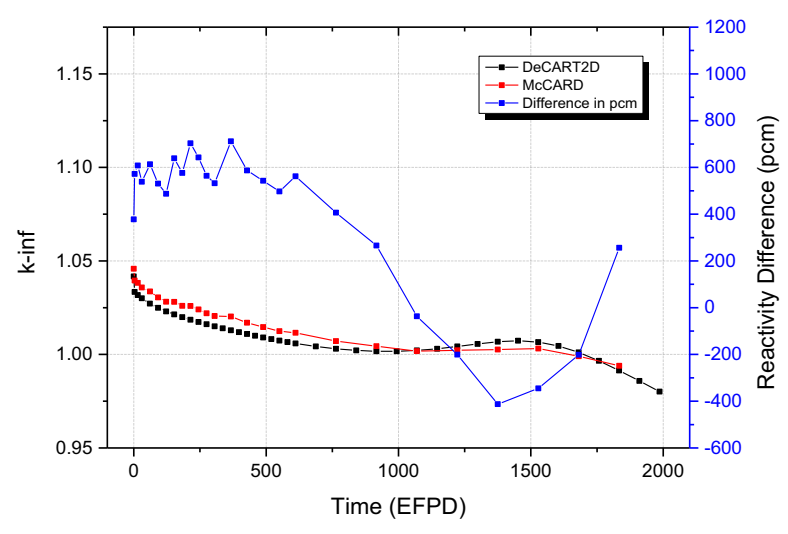

(c) B2 fuel assembly

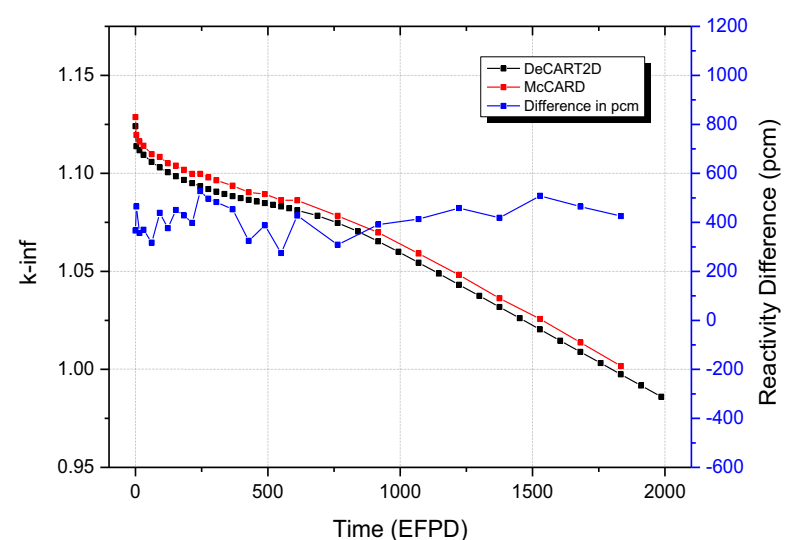

(b) B1 fuel assembly

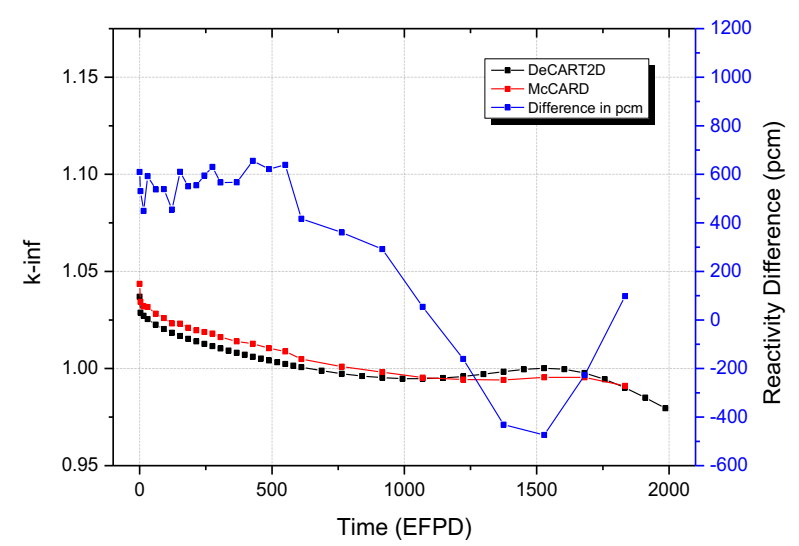

(d) B3 fuel assembly

Figure 2. Comparison of the infinite multiplication factors $\left(k_{\text {inf }}\right)$ for the B0, B1, B2 and B3 fuel assemblies calculated by McCARD and DeCART2D 
The excess reactivity was effectively controlled by the $\mathrm{Gd}_{2} \mathrm{O}_{3}$ burnable absorber in FCM BISO rods. Especially, the $\mathrm{B} 2$ and $\mathrm{B} 3$ fuel assemblies have extremely low excess reactivity during depletion due to the loading of large amount of $\mathrm{Gd}_{2} \mathrm{O}_{3}$ burnable absorber. They were loaded in the SMR core in order to flatten the power distribution in the core. Although the B3 fuel assembly has a negative reactivity after 800 EFPD, the degradation of cycle length is minimized by loading a small number of these type fuel assemblies into appropriate positions in the core. Figure 3 shows the comparison of MTCs of the B0, B1, B2 and B3 fuel assemblies calculated by McCARD. The MTCs were estimated to be less negative as the amount of burnable absorber increases. All of the MTCs were shown to be within the comparable range of commercial PWRs.

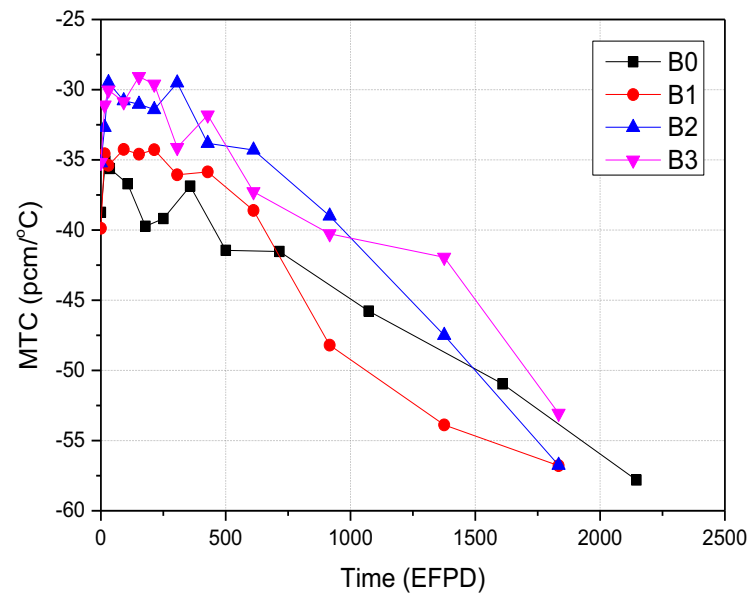

Figure 3. Comparison of the moderator temperature coefficients (MTC) of the fuel assemblies calculated by McCARD

\section{SMR CORE DESIGN AND ANALYSIS}

The SMR core has the power rate of $330 \mathrm{MWth}(100 \mathrm{MWe})$ and 57 fuel assemblies are loaded in the core. The active core height is $200 \mathrm{~cm}$ and all of burnable absorber rods have upper axial cutback region of 20 $\mathrm{cm}$ which has no BISO particles in order to flatten axial power distribution. Prior to considering the TRU multi-recycling, a reload core analysis on transition cycles loaded with the four fuel assemblies described above was performed with three batch refueling scheme. In this analysis, TRU recycling are not considered in order to facilitate the search of equilibrium cycle in which the neutronic characteristics are converged from view point of $\mathrm{CBC}$ within $10 \mathrm{ppm}$ compared to its previous cycle. Finally, the $5^{\text {th }}$ cycle was determined as the equilibrium cycle at which 20 fresh fuel assemblies are charged at BOC and 20 fuel assemblies ( 3 twice-burnt, 17 thrice-burnt) are discharged at EOC. Figure 4 shows the core loading pattern of $5^{\text {th }}$ equilibrium cycle at BOC. 


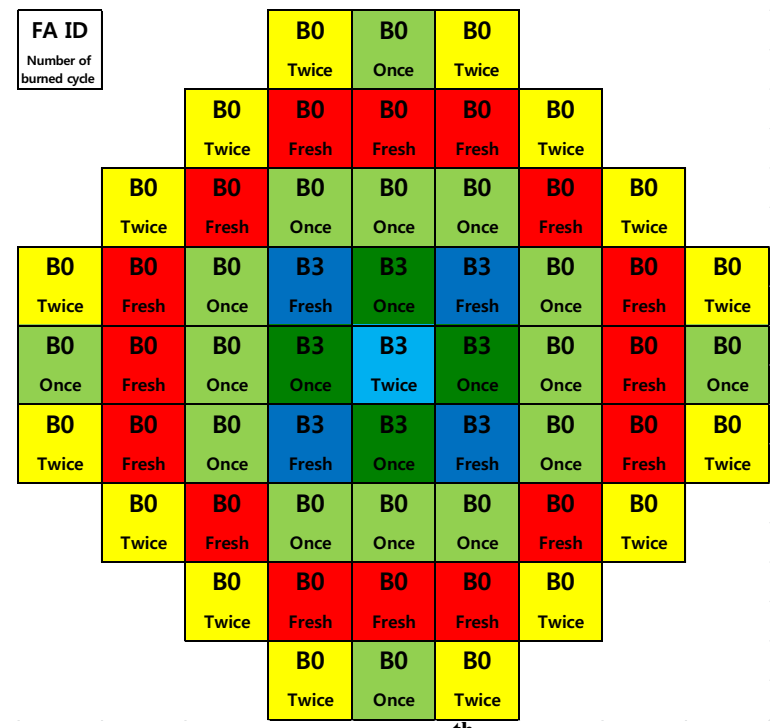

Figure 4. Core loading pattern of $5^{\text {th }}$ equilibrium cycle at BOC

After $5^{\text {th }}$ equilibrium cycle (i.e., from $6^{\text {th }}$ cycle core), the reload core analysis was performed with TRU recycling scheme. The recycling scheme of TRU nuclides is depicted in Figure 5. As shown in the figure, it is assumed that only the TRUs in MOX rods are totally recycled through reprocessing after discharge (5 years cooling and 2 years reprocessing and fabrication). The reprocessed TRUs are loaded into MOX rods of the fuel assembly for the next cycle and the remaining HM amount in the MOX rods are supplemented with $4.95 \mathrm{wt} \%$ enriched $\mathrm{UO}_{2}$. On the other hand, the TRUs in FCM TRISO rods are disposed without recycling and the subsequent FCM TRISO rods are always made up only with external TRU from PWR spent fuel corresponding to the burnup of $50 \mathrm{MWD} / \mathrm{kg}$ with 10 years cooling. With this strategy, the amount of reprocessed TRU can be significantly reduced at reprocessing stage by disposing the TRUs in FCM fuel after discharge without recycling. Also, a considerable high TRU consumption rate can be achieved in FCM rods throughout every cycle due to the supplement of the external TRU of high fissile $\mathrm{Pu}$ content every cycle.

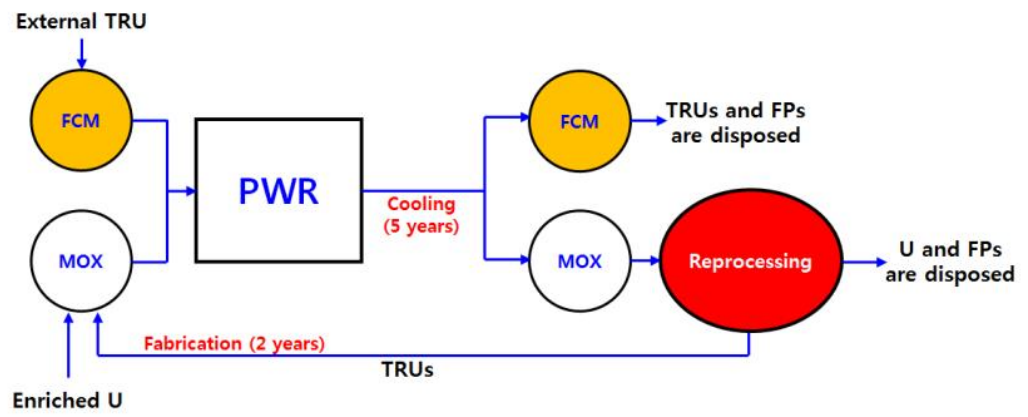

Figure 5. TRU recycling scheme of fuel assembly composed of MOX rods and FCM rods

The reload core analysis with TRU multi-recycling was performed up to $14^{\text {th }}$ cycle core in which the fuel assemblies of all batches contain thrice-recycled TRUs at BOC. The core loading patterns of the reload cores with TRU multi-recycling up to $14^{\text {th }}$ cycle are same as the $5^{\text {th }}$ equilibrium cycle. Figure 6 shows the changes of the critical boron concentration (CBC) over the cycles. From Figure 5, it is noted that the cycle lengths considerably decrease as TRU multi-recycling from 665 EFPD in $5^{\text {th }}$ cycle to 443 EFPD in $14^{\text {th }}$ cycle. This is because the quality of TRU as a fuel is degraded as recycling. The neutronic characteristics of the cores calculated by DeCART2D/MASTER and McCARD/MASTER two-step procedures are 
summarized in Table III. As shown in the table, the difference in cycle length between two code systems was evaluated to be 5 EFPD at the $5^{\text {th }}$ equilibrium cycle and it was evaluated within 20 EFPD throughout all of the cycles from $6^{\text {th }}$ to $14^{\text {th }}$ cycle. The results of two code systems showed good agreements for all neutronic characteristics. All the parameters are within the typical ranges of the PWRs. In particular, it is noted that the MTCs become more negative at BOC as TRU recycling proceeds because the CBC at BOC decreases as recycling.

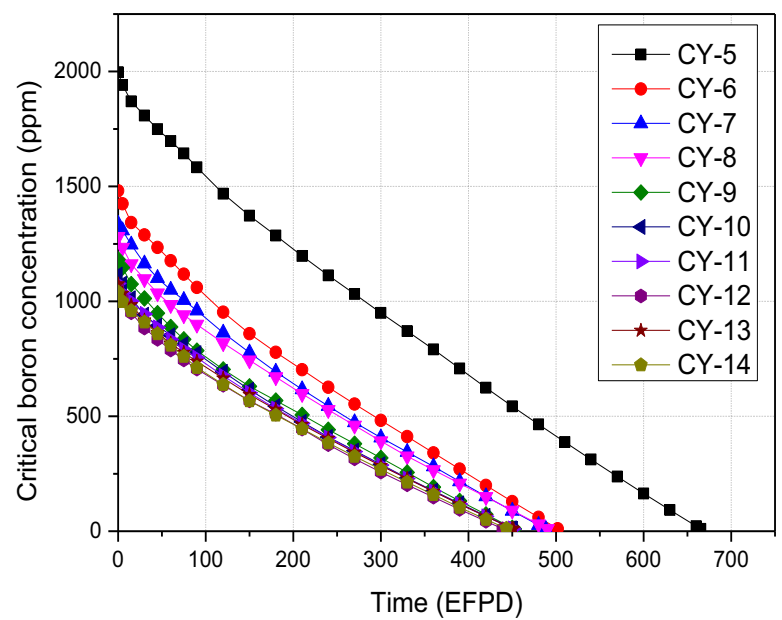

Figure 6. Comparison of cycle-wise critical boron concentration calculated by McCARD/MASTER two-step procedure $\left(5^{\text {th }}\right.$ to $14^{\text {th }}$ cycles $)$

Table III. Summary of neutronic characteristics from $5^{\text {th }}$ to $14^{\text {th }}$ cycles calculated by McCARD/MASTER and DeCART2D/MASTER two-step code procedures

\begin{tabular}{|c|c|c|c|c|c|c|c|c|c|c|c|}
\hline & & CY-5 & CY-6 & CY-7 & CY-8 & CY-9 & CY-10 & CY-11 & $\mathrm{CY}-12$ & CY-13 & CY-14 \\
\hline \multirow{2}{*}{ Cycle length (EFPD) } & ${ }^{*} \mathrm{M}-\mathrm{M}$ & 665 & 502 & 488 & 490 & 452 & 451 & 451 & 439 & 451 & 443 \\
\hline & ${ }^{*} \mathrm{D}-\mathrm{M}$ & 671 & 522 & 503 & 500 & 463 & 458 & 457 & 458 & 458 & 460 \\
\hline \multirow{2}{*}{ Max. CBC (ppm) } & M-M & 1997 & 1481 & 1337 & 1281 & 1183 & 1117 & 1078 & 1062 & 1075 & 1040 \\
\hline & D-M & 1936 & 1343 & 1189 & 1154 & 1023 & 983 & 970 & 957 & 947 & 950 \\
\hline \multirow{2}{*}{$\mathrm{AO}(\%)$} & $\mathrm{M}-\mathrm{M}$ & $\begin{array}{l}-4.2 \sim \\
-3.7\end{array}$ & $\begin{array}{l}-5.1 \sim \\
-4.3\end{array}$ & $\begin{array}{l}-5.5 \sim \\
-4.6\end{array}$ & $\begin{array}{l}-6.0 \sim \\
-4.9\end{array}$ & $\begin{array}{l}-5.8 \sim \\
-5.0\end{array}$ & $\begin{array}{l}-6.3 \sim \\
-5.1\end{array}$ & $\begin{array}{l}-6.0 \sim \\
-5.0\end{array}$ & $\begin{array}{l}-6.1 \sim \\
-5.3\end{array}$ & $\begin{array}{l}-6.5 \sim \\
-5.3\end{array}$ & $\begin{array}{l}-6.5 \sim \\
-5.3\end{array}$ \\
\hline & D-M & $\begin{array}{l}-4.1 \sim \\
-3.6\end{array}$ & $\begin{array}{l}-5.1 \sim \\
-4.5 \\
\end{array}$ & $\begin{array}{l}-6.0 \sim \\
-5.2\end{array}$ & $\begin{array}{l}-6.3 \sim \\
-5.3 \\
\end{array}$ & $\begin{array}{l}-6.4 \sim \\
-5.5 \\
\end{array}$ & $\begin{array}{l}-6.7 \sim \\
-5.7\end{array}$ & $\begin{array}{l}-6.8 \sim \\
-5.7 \\
\end{array}$ & $\begin{array}{l}-6.8 \sim \\
-5.7\end{array}$ & $\begin{array}{l}-6.8 \sim \\
-5.6\end{array}$ & $\begin{array}{l}-6.8 \sim \\
-5.6\end{array}$ \\
\hline \multirow{2}{*}{ Max. Fq } & M-M & 2.14 & 2.06 & 1.96 & 1.99 & 1.95 & 1.97 & 1.98 & 2.03 & 2.01 & 2.03 \\
\hline & D-M & 2.02 & 2.00 & 1.97 & 1.98 & 1.97 & 1.95 & 1.95 & 1.95 & 1.95 & 1.95 \\
\hline \multirow{2}{*}{ Max. Fr } & M-M & 1.54 & 1.44 & 1.45 & 1.47 & 1.44 & 1.45 & 1.46 & 1.49 & 1.48 & 1.48 \\
\hline & D-M & 1.54 & 1.54 & 1.46 & 1.46 & 1.45 & 1.43 & 1.43 & 1.43 & 1.43 & 1.43 \\
\hline \multirow{2}{*}{$\begin{array}{l}\mathrm{MTC}(\mathrm{pcm} / \mathrm{oC}) \\
\mathrm{BOC} / \mathrm{EOC} \text { at } \mathrm{HFP}\end{array}$} & M-M & $\begin{array}{l}-41.56 / \\
-66.02\end{array}$ & $\begin{array}{l}-48.42 / \\
-65.90\end{array}$ & $\begin{array}{l}-48.70 / \\
-63.81\end{array}$ & $\begin{array}{l}-48.83 / \\
-63.61\end{array}$ & $\begin{array}{l}-49.36 / \\
-64.97\end{array}$ & $\begin{array}{l}-50.42 / \\
-63.17\end{array}$ & $\begin{array}{l}-49.27 / \\
-62.98\end{array}$ & $\begin{array}{l}-50.10 / \\
-64.58\end{array}$ & $\begin{array}{l}-51.95 / \\
-65.02\end{array}$ & $\begin{array}{l}-51.87 / \\
-65.45\end{array}$ \\
\hline & D-M & $\begin{array}{l}-41.18 / \\
-67.83\end{array}$ & $\begin{array}{l}-47.69 / \\
-67.11\end{array}$ & $\begin{array}{l}-49.36 / \\
-66.59\end{array}$ & $\begin{array}{l}-49.76 / \\
-66.46\end{array}$ & $\begin{array}{l}-51.4 / \\
-66.44\end{array}$ & $\begin{array}{l}-51.99 / \\
-66.49\end{array}$ & $\begin{array}{l}-52.18 / \\
-66.53\end{array}$ & $\begin{array}{l}-52.51 / \\
-66.77\end{array}$ & $\begin{array}{l}-52.76 / \\
-67.02\end{array}$ & $\begin{array}{l}-52.81 / \\
-67.15\end{array}$ \\
\hline \multirow{2}{*}{$\begin{array}{l}\text { Avg. discharge BU } \\
(\mathrm{MWD} / \mathrm{kg})\end{array}$} & M-M & 53.76 & 50.84 & 45.91 & 40.21 & 39.36 & 38.18 & 36.90 & 36.70 & 36.58 & 36.40 \\
\hline & D-M & 55.21 & 52.03 & 47.18 & 41.39 & 40.29 & 38.99 & 37.53 & 37.50 & 37.51 & 37.52 \\
\hline
\end{tabular}

*M-M: McCARD-MASTER code procedure, ${ }^{*}$ D-M: DeCART2D-MASTER code procedure 
The analysis of TRU mass flow in the core was conducted to evaluate the TRU consumption performance of the SMR core. Table IV shows the summary of the TRU mass flow for each cycle calculated by McCARD/MASTER and DeCART2D/MASTER two-step procedures. For consistent comparison, four cores corresponding to $5^{\text {th }}, 8^{\text {th }}, 11^{\text {th }}$, and $14^{\text {th }}$ cycles are considered. The $5^{\text {th }}$ cycle core is comprised of the fresh, once-burnt, and twice-burnt fuel assemblies that contains only not recycled TRUs and the $8^{\text {th }}$ cycle core is comprised of the fresh, once-burnt, and twice-burnt fuel assemblies containing only once recycled TRUs in MOX rods. Similarly, the $11^{\text {th }}$ and $14^{\text {th }}$ cycle cores are loaded with fresh, once-burnt, and twiceburnt assemblies of twice and thrice recycled TRUs in MOX rods, respectively. As shown in Table IV, total TRU consumption rate calculated by the McCARD/MASTER code system was evaluated to be similar to those of the DeCART2D/MASTER code system. Also, at $14^{\text {th }}$ cycle, the fact that the production of $\mathrm{Pu}$ by radiative capture of ${ }^{238} \mathrm{U}$ starts to be larger than the consumption of $\mathrm{Pu}$ was same for both McCARD/MASTER and DeCART2D/MASTER code systems. For the $5^{\text {th }}$ cycle core, the FCM rods have a high TRU consumption rate of $26.3 \%$ but the MOX rods have a low TRU consumption rate of $8.1 \%$, which leads to a net TRU consumption rate of $14.3 \%$. Total consumption rate was reduced by $\sim 41 \%$ from $14.33 \%$ in $5^{\text {th }}$ cycle to $8.46 \%$ in $14^{\text {th }}$ cycle. The consumption rate of the FCM rods was slightly decreased by $\sim 25 \%$ from $26.27 \%$ to $19.73 \%$ while that of the MOX rods was significantly reduced by $\sim 81 \%$ from $8.13 \%$ in $5^{\text {th }}$ cycle to $1.52 \%$ in $14^{\text {th }}$ cycle. The slight decrease of TRU consumption rate in FCM rods is due to the fact that only external TRU feed (i.e., not recycled TRU) is used in FCM rods. In MOX rods, it is noted that a negative plutonium consumption rate of $-0.4 \%$ in $14^{\text {th }}$ cycle meaning a slight production of plutonium occurs, which is due to the degradation of TRU quality as recycling. On the other hand, MA (Minor Actinide) consumption rates are all significantly positive in both MOX and FCM rods for all the cycles.

Table IV. Summary of TRU mass flow analysis for $5^{\text {th }}, 8^{\text {th }}, 11^{\text {th }}$, and $14^{\text {th }}$ cycle calculated by McCARD/MASTER and DeCART2D/MASTER two-step procedures

\begin{tabular}{|c|c|c|c|c|c|c|c|c|c|c|}
\hline \multirow{2}{*}{ Cycle } & & \multicolumn{3}{|c|}{ Plutonium } & \multicolumn{3}{|c|}{ Minor actinides } & \multicolumn{3}{|c|}{ TRU (Pu+MA) } \\
\hline & & MOX & $\mathrm{FCM}$ & Total & MOX & FCM & Total & MOX & FCM & Total \\
\hline \multirow{3}{*}{$\begin{array}{c}5 \\
\left({ }^{*} \mathrm{M}-\mathrm{M}\right)\end{array}$} & Charged (kg) & 244.44 & 127.06 & 371.50 & 46.03 & 23.93 & 69.96 & 290.47 & 150.99 & 441.46 \\
\hline & Discharged (kg) & 227.07 & 92.05 & 319.12 & 39.79 & 19.27 & 59.06 & 266.86 & 111.32 & 378.18 \\
\hline & Consumption rate $(\%)$ & 7.10 & 27.55 & 14.10 & 13.56 & 19.48 & 15.59 & 8.13 & 26.27 & 14.33 \\
\hline \multirow{3}{*}{$\left(\begin{array}{c}5 \\
\left({ }^{*} \mathrm{D}-\mathrm{M}\right)\end{array}\right.$} & Charged (kg) & 244.42 & 127.07 & 371.49 & 46.02 & 23.92 & 69.94 & 290.44 & 150.99 & 441.43 \\
\hline & Discharged (kg) & 227.30 & 91.68 & 318.99 & 39.10 & 18.62 & 57.72 & 266.41 & 110.30 & 376.71 \\
\hline & Consumption rate $(\%)$ & 7.00 & 27.85 & 14.13 & 15.02 & 22.16 & 17.46 & 8.27 & 26.95 & 14.66 \\
\hline \multirow{3}{*}{$\begin{array}{c}8 \\
\left({ }^{*} \mathrm{M}-\mathrm{M}\right)\end{array}$} & Charged (kg) & 219.71 & 127.06 & 346.77 & 47.02 & 23.93 & 70.95 & 266.73 & 150.99 & 417.72 \\
\hline & Discharged (kg) & 214.64 & 99.04 & 313.68 & 40.88 & 20.28 & 61.16 & 255.51 & 119.32 & 374.84 \\
\hline & Consumption rate $(\%)$ & 2.31 & 22.05 & 9.54 & 13.06 & 15.24 & 13.80 & 4.21 & 20.97 & 10.27 \\
\hline \multirow{3}{*}{$\begin{array}{c}8 \\
\left({ }^{*} \mathrm{D}-\mathrm{M}\right)\end{array}$} & Charged (kg) & 220.09 & 127.07 & 347.17 & 45.66 & 23.92 & 69.59 & 265.76 & 150.99 & 416.75 \\
\hline & Discharged (kg) & 215.71 & 98.66 & 314.37 & 39.75 & 19.71 & 59.46 & 255.46 & 118.37 & 373.83 \\
\hline & Consumption rate $(\%)$ & 1.99 & 22.36 & 9.45 & 12.96 & 17.60 & 14.55 & 3.88 & 21.61 & 10.30 \\
\hline \multirow{3}{*}{$\begin{array}{c}11 \\
\left({ }^{*} \mathrm{M}-\mathrm{M}\right)\end{array}$} & Charged (kg) & 207.95 & 127.06 & 335.01 & 46.12 & 23.93 & 70.05 & 254.07 & 150.99 & 405.06 \\
\hline & Discharged (kg) & 206.90 & 100.65 & 307.55 & 40.86 & 20.52 & 61.39 & 247.76 & 121.18 & 368.94 \\
\hline & Consumption rate $(\%)$ & 0.51 & 20.78 & 8.20 & 11.41 & 14.23 & 12.37 & 2.48 & 19.74 & 8.92 \\
\hline \multirow{3}{*}{$\left(\begin{array}{c}11 \\
\left({ }^{*} \mathrm{D}-\mathrm{M}\right)\end{array}\right.$} & Charged (kg) & 209.12 & 127.07 & 336.19 & 44.48 & 23.92 & 68.40 & 253.60 & 150.99 & 404.59 \\
\hline & Discharged (kg) & 208.64 & 100.60 & 309.24 & 39.60 & 20.03 & 59.63 & 248.25 & 120.63 & 368.87 \\
\hline & Consumption rate $(\%)$ & 0.23 & 20.83 & 8.02 & 10.96 & 16.27 & 12.82 & 2.11 & 20.11 & 8.83 \\
\hline \multirow{3}{*}{$\begin{array}{c}14 \\
\left({ }^{*} \mathrm{M}-\mathrm{M}\right)\end{array}$} & Charged (kg) & 200.29 & 127.06 & 327.35 & 44.92 & 23.93 & 68.84 & 245.21 & 150.99 & 396.20 \\
\hline & Discharged (kg) & 201.10 & 100.69 & 301.78 & 40.39 & 20.52 & 60.90 & 241.48 & 121.21 & 362.69 \\
\hline & Consumption rate $(\%)$ & -0.40 & 20.76 & 7.81 & 10.09 & 14.25 & 11.53 & 1.52 & 19.73 & 8.46 \\
\hline \multirow{3}{*}{$\begin{array}{c}14 \\
\left({ }^{*} \mathrm{D}-\mathrm{M}\right)\end{array}$} & Charged (kg) & 202.00 & 127.07 & 329.07 & 43.21 & 23.92 & 67.13 & 245.21 & 150.99 & 396.20 \\
\hline & Discharged (kg) & 203.26 & 100.33 & 303.58 & 39.07 & 19.98 & 59.04 & 242.32 & 120.31 & 362.63 \\
\hline & Consumption rate $(\%)$ & -0.62 & 21.05 & 7.74 & 9.59 & 16.49 & 12.05 & 1.18 & 20.32 & 8.47 \\
\hline
\end{tabular}

Table V summarizes the overall mass balance of $U$ and TRU from $5^{\text {th }}$ to $14^{\text {th }}$ cycle. The amount of external uranium feed for MOX fuels loaded in all of cycle at BOC is $36,105 \mathrm{~kg}$ while the consumed 
amount of uranium is $1,336 \mathrm{~kg}$ and $34,768 \mathrm{~kg}$ uranium is sent to repository. The TRUs in MOX fuels are externally supplied by $290 \mathrm{~kg}$ only in $5^{\text {th }}$ cycle at BOC and it is recycled through $5^{\text {th }}$ to $14^{\text {th }}$ cycle without external TRU feed. Finally, $241 \mathrm{~kg}$ TRU discharged from $14^{\text {th }}$ cycle at EOC is disposed. In case of the TRU in FCM fuels, the amount of external TRU feed loaded at BOCs through $5^{\text {th }}$ to $14^{\text {th }}$ cycles is 1,510 $\mathrm{kg}$ and the TRU of $1,186 \mathrm{~kg}$ is discharged, at which the consumed mass is $323 \mathrm{~kg}$. In the aspect of overall mass balance of TRU through $5^{\text {th }}$ to $14^{\text {th }}$ cycle, the amount of external TRU feed is $1,800 \mathrm{~kg}$ and $1,428 \mathrm{~kg}$ is discharged, which corresponds to the TRU consumption rate of $20.69 \%$.

Table V. Overall mass balance of $U$ and TRU from $5^{\text {th }}$ to $14^{\text {th }}$ cycle calculated by McCARD/MASTER two-step procedure

\begin{tabular}{|l|c|}
\hline \multicolumn{1}{|c|}{ Items } & Values (in kg) \\
\hline Uranium external feed through MOX fuels (A) & 36,105 \\
Uranium consumption through MOX fuels (B) & 1,336 \\
Discharged uranium from MOX fuels (C = A - B) & 34,768 \\
\hline TRU external feed through MOX fuels (D) & 290 \\
TRU consumption through MOX fuels (E) & 49 \\
Discharged TRU from MOX fuels at EOC of $7^{\text {th }}$ cycle (F = D - E) & 241 \\
\hline TRU external feed through FCM fuels (G) & 1,510 \\
TRU consumption through FCM fuels (H) & 323 \\
Discharged TRU through FCM fuels (I = G - H) & 1,186 \\
\hline Total TRU external feed ( $=\mathrm{D}+\mathrm{G})$ & 1,800 \\
Total TRU consumption (K = E $+\mathrm{H})$ & 372 \\
Total TRU to be disposed after $14^{\text {th }}$ cycle (L= J - K) & 1,428 \\
Total TRU consumption rate $(\%, \mathrm{M}=\mathrm{K} / \mathrm{J} \times 100)$ & $20.69 \%$ \\
\hline
\end{tabular}

\section{CONCLUSIONS}

In this study, a small modular PWR core was designed and analyzed in detail for TRU multi-recycling with McCARD/MASTER two-step procedure in which the lattice calculation was performed by a Monte Carlo code called McCARD with a continuous energy library. We considered a new TRU recycling concept using a new fuel assembly design comprised of FCM and MOX fuel rods. In this concept, TRUs only in the MOX fuel rods are recycled while FCM fuel rods are used to achieve deep burning of TRU without recycling. The reload core analysis was performed initially without TRU recycling for facilitating the search of equilibrium cycle $\left(5^{\text {th }}\right.$ cycle) and the subsequent reload core analysis was conducted with TRU recycling from $6^{\text {th }}$ to $14^{\text {th }}$ cycle core which is loaded with the fuel assemblies with thrice recycled TRUs in MOX fuel rods. From the analysis, it was found that 1) the analysis on the neutronic characteristics and TRU mass flow using the McCARD/MASTER code system shows good agreement with the previous ones obtained using the DeCART2D/MASTER code system, 2) the cycle lengths of the core considerably decrease as TRU recycling from 665 EFPD in $5^{\text {th }}$ cycle to 443 EFPD in $14^{\text {th }}$ cycle, 3 ) the net TRU consumption rate of the core was estimated to be 8.46 14.33\%, and the FCM rods have a high TRU consumption rate of 19.73 26.27 \% during TRU recycling, and 4) overall TRU consumption rate through all of the cycles with TRU recycling was estimated to be $20.69 \%$. In conclusion, it is neutronically feasible to design PWR-based SMR core such that it has a significant net TRU consumption rate with TRU multi-recycling.

\section{ACKNOWLEDGMENTS}

This work was supported by National Research Foundation of Korea (NRF) through project No. 2016M2B2A9911611. 


\section{REFERENCES}

1. T. K. kim et al., "ASSESSMENT OF TRANSURANICS STABILIZATION IN PWRs," Proceedings of PHYSOR 2002, Seoul, Korea, October 7-10, 2002.

2. T. K. kim et al., "Assessment of the Equilibrium State in Reactor-Based Plutonium or Transuranics Multirecycling," Proc. $7^{\text {th }}$ Information Exchange Mtg. Actinide and Fission Product Partitioning and Transmutation, Jeju, Korea, October 14-16, 2002.

3. G. Youinou et al., "Plutonium Multirecycling in Standard PWRs Loaded with Evolutionary Fuels," Nuclear Science and Engineering, Vol. 151, p. 25-45, 2005.

4. E. Shwageraus et al., "A Combined Nonfertile and $\mathrm{UO}_{2}$ PWR Fuel Assembly for Actinide Waste Minimization," Nuclear Technology, Vol. 149, p. 281-303, 2005.

5. D. H. Hwang. J. Y. Choi, and S. G. Hong., "TRU transmutation in Light Water Cooled SMR cores loaded with Fuel Assemblies composed of MOX and FCM fuel rods," Transactions of the Korean Nuclear Society Autumn Meeting, Gyeongju, Korea, October 26-27, 2017.

6. D. H. Hwang, Y. S. Cho, and S. G. Hong., "TRU Multi-Recycling Analysis in SMR Core with MOX Rods and FCM Rods," ANS Winter Meeting, Orlando, FL, November 11-15, 2018.

7. Y. S. Cho, and S. G. Hong., "Physics analysis of new TRU recycling options using FCM and MOX fueled PWR assemblies," Accepted for publication in Nuclear Engineering and Technology.

8. J. Y. Cho et al., "DeCART2D v.1.0 User's Manual," KAERI/TR-5116/2013, Korea Atomic Energy Research Institute, 2013.

9. J. Y. Cho et al., "MASTER v4.0 User's Manual," KAERI/UM-41/2016, Korea Atomic Energy Research Institute, 2016.

10. H. J. Shim et al., "McCARD User's Manual," Monte Carlo Laboratory, Seoul National University, 2011.

11. G. Croff et al., "A User's Manual for the ORIGEN2 Computer Code," ORNL/TM-7175, Oak Ridge National Laboratory, 1980.

12. D. J. Kim et al., "Fabrication of micro-cell $\mathrm{UO}_{2}-\mathrm{Mo}$ pellet with enhanced thermal conductivity," Journal of Nuclear Materials, 462, 289-295, 2015. 